\title{
An emotions-informed approach for digital documentation of rural heritage landscapes: Baojiatun, a traditional tunpu village in Guizhou, China
}

\author{
Jane-Heloise Nancarrow ${ }^{1}$, Chen Yang ${ }^{2,3^{*}}$ (D) and Jing Yang ${ }^{4}$
}

\begin{abstract}
The application of digital technologies has greatly improved the efficiency of cultural heritage documentation and the diversity of heritage information. Yet the adequate incorporation of cultural, intangible, sensory or experimental elements of local heritage in the process of digital documentation, and the deepening of local community engagement, remain important issues in cultural heritage research. This paper examines the heritage landscape of tunpu people within the context of digital conservation efforts in China and the emergence of emotions studies as an evaluative tool. Using a range of data from the Ming-era village of Baojiatun in Guizhou Province, this paper tests an exploratory emotions-based approach and methodology, revealing shifting interpersonal relationships, experiential and praxiological engagement with the landscape, and emotional registers within tunpu culture and heritage management. The analysis articulates distinctive asset of emotional value at various scales and suggests that such approaches, applied within digital documentation contexts, can help researchers to identify multi-level heritage landscape values and their carriers. This methodology can provide more complete and dynamic inventories to guide digital survey and representation; and the emotions-based approach also supports the integration of disparate heritage aspects in a holistic understanding of the living landscape. Finally, the incorporation of community participation in the process of digital survey breaks down boundaries between experts and communities and leads to more culturally appropriate heritage records and representations.
\end{abstract}

Keywords: Digital documentation, Rural heritage landscapes, Digitisation, Emotions, Chinese heritage

\section{Introduction}

The application of digital technology to record cultural heritage has become an international trend in the field of heritage conservation in recent decades. UNESCO's Charter on the Preservation of Digital Heritage (2003) and the Vancouver Declaration on Digitisation and Preservation (2012), expanded the conventional

\footnotetext{
* Correspondence: chen.yang@tongji.edu.cn

${ }^{2}$ Department of Landscape Architecture, College of Architecture and Urban Planning, Tongji University, 1239 Siping Road, Shanghai 200092, People's Republic of China

${ }^{3}$ Key Laboratory of Ecology and Energy-saving Study of Dense Habitat, Ministry of Education, Shanghai, People's Republic of China

Full list of author information is available at the end of the article
}

understanding of cultural heritage to include digital representations as objects of conservation. Digital technology provides unprecedented perspectives, details, and precision to observe and record cultural heritage, which has had a revolutionary impact on the workflow of heritage documentation and offered opportunities to explore innovative conservation and management approaches. To date, the majority of digital cultural heritage projects focus on technical challenges, such as the methods and tools to quickly obtain accurate and complete information of physical space (Baptista 2013; Kivilcim and Duran 2016). Yet the focus of digital heritage research is gradually expanding to include theoretical and ethical 
aspects; paying attention to the integration of cultural, intangible, sensory or experiential elements within the documentation process of digital cultural heritage (Cormier 2017; Quintero et al. 2020), and underpinned by ethical principles which can inform and improve heritage recording practices (Quintero et al. 2020).

These issues are especially important in the field of landscape heritage, as heritage landscapes are the result of the gradual accumulation of cultural values and attributes within natural systems, in both their tangible and intangible dimensions (Lennon 2012). The essential elements of landscapes and their management closely relate to the communities which shape and occupy them (UNESCO 2009). Traditions, beliefs, and ongoing interactions between people and place make important contributions to the conservation and sustainable development of heritage landscapes (Yang 2015). However, the application of digital technologies in most digital projects privileges the spatial representation of tangible settings over other intangible dimensions (Flynn 2007). Characterised by an attention to mathematical accuracy and the placement of solids, the translation of the environment to geometry has become the hallmark of authenticity, and the application of digital tools has further strengthened the record of the physical environment (Flynn 2007). To a certain extent, intangible dimensions of heritage landscapes have been overlooked, yet the integration of intangible components into digital documentation processes and the deepening of community engagement remain critical to the quality of heritage landscape conservation. The aim of this paper is to present an emotions-based approach integrated within digital recording processes. This paper applies new approaches from emotions studies as an evaluative tool to bridge the gap between local tunpu (屯堡) communities and digital documentation practices for heritage landscapes. Its specific objectives are to (1) explore an emotions-based approach for digital heritage landscape documentation; (2) apply this approach to a rural heritage landscape in China; (3) identify the potential application and strengths of this approach.

\section{Building an emotions-informed approach for digital heritage documentation}

\subsection{Seeing heritage as an emotional practice}

Emotions studies consist of broad interdisciplinary approaches which reflect diverse perspectives, generally from humanities and social sciences fields such as anthropology, psychology, phenomenology and sociology, history, and cultural studies (Smith et al. 2018). These fields concentrate on the role of emotions as 'strong feelings deriving from one's circumstances, mood, or relationships with others', and also define emotions as 'complex reaction patterns, involving experiential, behavioural and physiological elements' (American Psychological Association 2021). Emotions function as social and relational expressions, not only formed between people but also between people and places/sites/objects. As Sara Ahmed has explored in her concept of 'sticky and circulating emotions', people experience emotional entanglements as specific sites within their culture and environment (2004). Heritage is increasingly recognised as an emotional practice and experience; and the role of emotions is receiving increasing attention in heritage scholarship-most commonly in studies of affective responses of visitors to sites, and as participants in heritage production processes (Liebelt 2019; DomínguezQuintero et al. 2019). Recent research in heritage has emphasised an understanding of emotions as a powerful link connecting heritage, people, value, and experience; such as the bodily expression of emotions as historically, socially, and culturally dependent, and how emotions frameworks such as empathy can be purposefully employed to foster imaginative engagement with others in interpretive sites such as museums and heritage precincts (Keightley and Pickering 2012).

\subsection{Integrating emotions study into digital heritage documentation}

The identification of emotional connections between people and heritage landscapes has the potential to add significant value to current digital heritage documentation practices. Digital heritage reconstructions, such as 3D modelling and panoramic space, take photorealism or its simulated geometric 3D equivalent as the standard model of vision (Flynn 2007). The result is a directional space that reduces the complexity of spatial experience down to an XYZ grid of mathematical absolutes, lacking in human scale, or social and cultural presence (Flynn 2007). Historic Landscape Characterisation (HLC) methodologies provided guidance for the investigation and recording of heritage landscapes, and hold inherent possibilities for capturing emotions to articulate complexities and in human behaviour, values, social interaction, and experiential engagement with landscapes (Turner 2006; Williamson 2007; Fairclough and Herring 2016). With the addition of digital approaches, there is great potential for documentation to present new, additional perspectives for curating the fluid and multifarious emotional engagements that exist within historic landscapes (Turk 2019). This paper outlines opportunities to include more representative cultural and phenomenological elements as part of digital documentation, by considering how to capture emotional values of heritage sites and assets in the technological processes of digital heritage. The investigation and identification of collective emotions contained within heritage landscapes enhances our understanding 
of local heritage value, and facilitates a more comprehensive and meaningful conservation and management.

\subsection{Building an emotions-based framework for heritage landscape identification}

The rich and complex connections between people and places within heritage landscapes can be explored using an emotions-based framework. Emotions are constructed within cultural contexts through practice-based process of socialisation; as such, they are 'individually and collectively experienced and require sustained interpersonal interaction in order to endure' (Sather-Wagstaff 2016, 191). To deeply understand the emotions contained in heritage landscapes, it is necessary to investigate the historical, cultural, and social contexts of a site and its communities. In some cases, the dominance of emotional themes over others within a local community manifests within communal interaction and wider acculturation, and plays out onto objects and surrounding environments (Reckwitz 2012). While individual emotions about place, history, and landscape consistently change due to shifting social contexts, collective emotions along certain themes accumulate through long-term interaction within the landscape. Feelings are expressed through specific emotional moods or themes, usually associated with specific landscape features, and the intensity and the duration of a feeling represents its strength. Strong, shared, and continuous feelings can then become relatively stable and continuous responses to landscape environments and features.

This paper identifies both specific feelings in relation to a site or object; and also objects or sites that produce intense emotions which can then provide important guidance and reference for digital survey and documentation. These objects or sites are defined as assets with intense emotional value (hereafter AIEV). AIEV are places/things recognised as emotionally meaningful (in this case, to the local community who inhabit the heritage landscape) but not necessarily where people share the same affective experience about the asset. This methodology builds on the concept of 'Feeling Maps', which plot episodes or experiences of heightened positive and negative emotions within geographical spaces or features as 'feeling intensities' or 'emotional hotspots' (Marchant 2019; Turk 2019; Broomhall and Pickering 2012; Weinreb and Rofè 2013). AIEVs exist at multiscale levels and are neither static nor universal. They are tied to constantly shifting interpersonal interactions over the course of a landscape's historical development, and thus can be defined as 'perceived historic and living'.

\section{Case study: Baojiatun Village}

\subsection{Tunpu culture and Baojiatun Village}

Типри culture was a product of military colonisation in central Guizhou Province in southwestern China during the Ming Dynasty. In the early Ming period (the late 14th century) waves of Han immigrants were settled in regional Guizhou by the central Chinese government following military incursions in the south-west of China (Wu and Gong 2009). Tun refers to the settlements established by military immigrants and their families for defence at that time, while $p u$ refers to the settlements established by immigrants who came later and whose main function was local colonial occupation. According to historical and archaeological research, there were approximately more than 100 tun villages and more than $150 p u$ villages in Guizhou Province. The settlement pattern of these sites indicates that the defensive characteristics of $\mathrm{pu}$ settlements were positioned to geographically surround tun (Wu and Gong 2009; Luo 2014) (Fig. 1). With the passage of time and the abolition of the military immigration policy, the boundary between tun and $p u$ gradually blurred, and merged into one word tuпри. Therefore, tипри culture is the result of the migration of Han culture from the northern part of China to central Guizhou, and has continued to develop for more than 600 years.

Baojiatun Village was originally a tun village with a long history of military settlement. Baojiatun (the village of Bao's family) is named for its inhabitants, most of whom share the same surname of 'Bao', to which popular oral genealogical traditions ascribe their origins. Bao Fubao-a general dispatched to guard the region during the Ming Dynasty-established the village and its defensive layout (Wu 2010). According to archaeological survey, it is likely that the village itself was originally designed and built as barracks; with karst limestone peaks surrounding the open lowlands where Baojiatun is located forming a natural defensive barrier for the village (Fig. 2). A river flows through the southern part of the village, where General Bao and his soldiers built a sub-dam to divide the river into two and built seven dams and five channels to form a complete water conservancy system to meet the village's flood control and agricultural irrigation needs. The lower ground around the village has been used as land for agricultural production since this time, and the forest on the karst hills has been protected for generations. There are more than 2000 residents living in the village today, providing an opportunity to work with a living local culture to explore this inclusive approach for digital heritage landscape documentation.

\subsection{Research methods and process}

The research was designed and conducted as a digital documentation process co-produced with local people, as a validating heritage practice. It commenced with a desk-based review of documentary sources, photos, drawings, and maps to understand the context and the history of Baojiatun. The project team also examined 


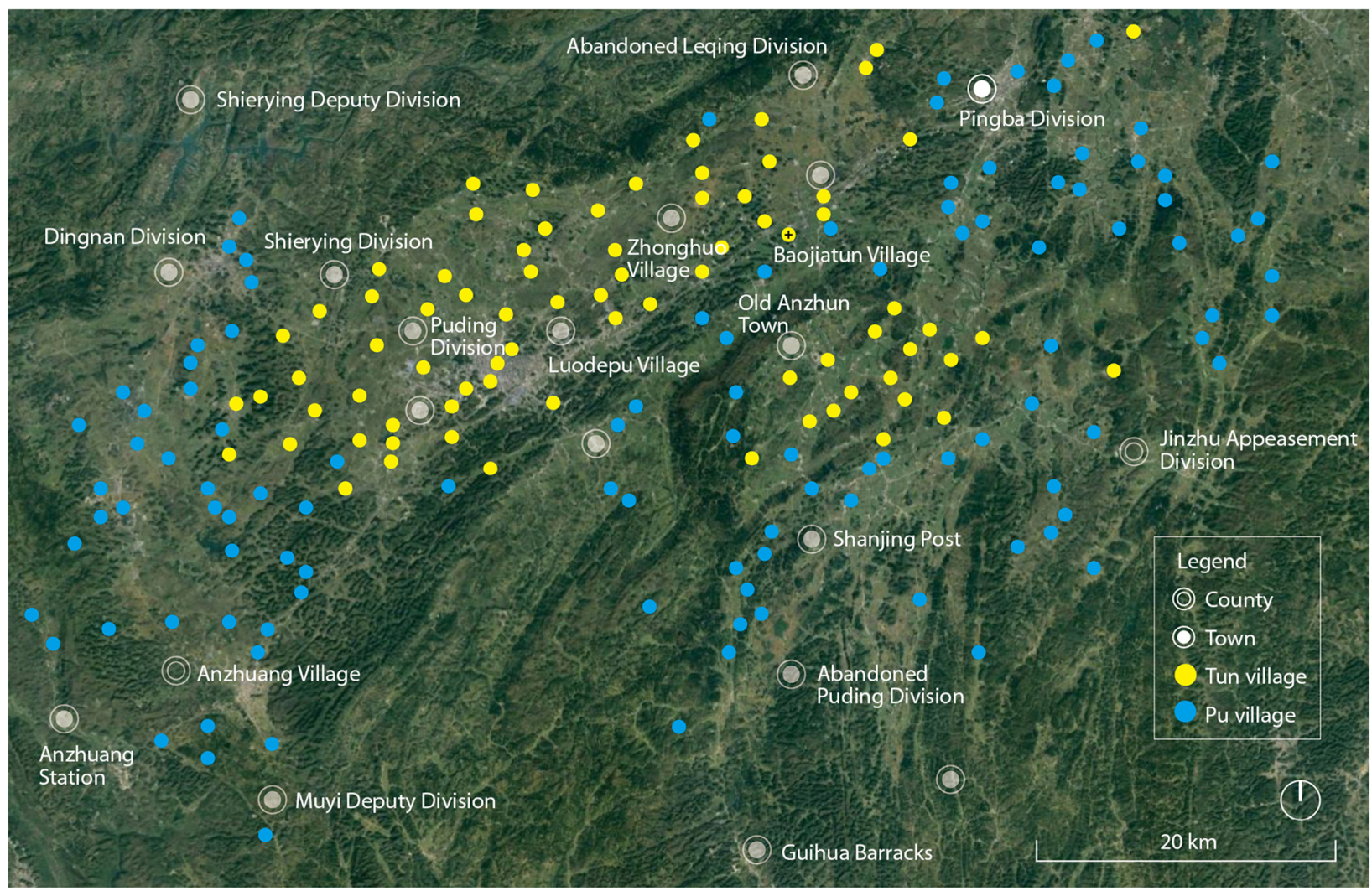

Fig. 1 Ming era distribution of tunpu village (Source: the authors)

conventional historical source material and archaeological evidence such as local chronicles and textual accounts. The history, significance, and current status of the village were explored to establish the scope of the heritage survey and the context for an emotions-based approach (Fig. 3).
The examination of the emotional connections between Baojiatun and local community was conducted prior to the digital survey (Fig. 3). Ethnographic survey captured audio-visual recordings of local people's activities at specific sites. These recordings documented intangible cultural practices such as festivals, traditional

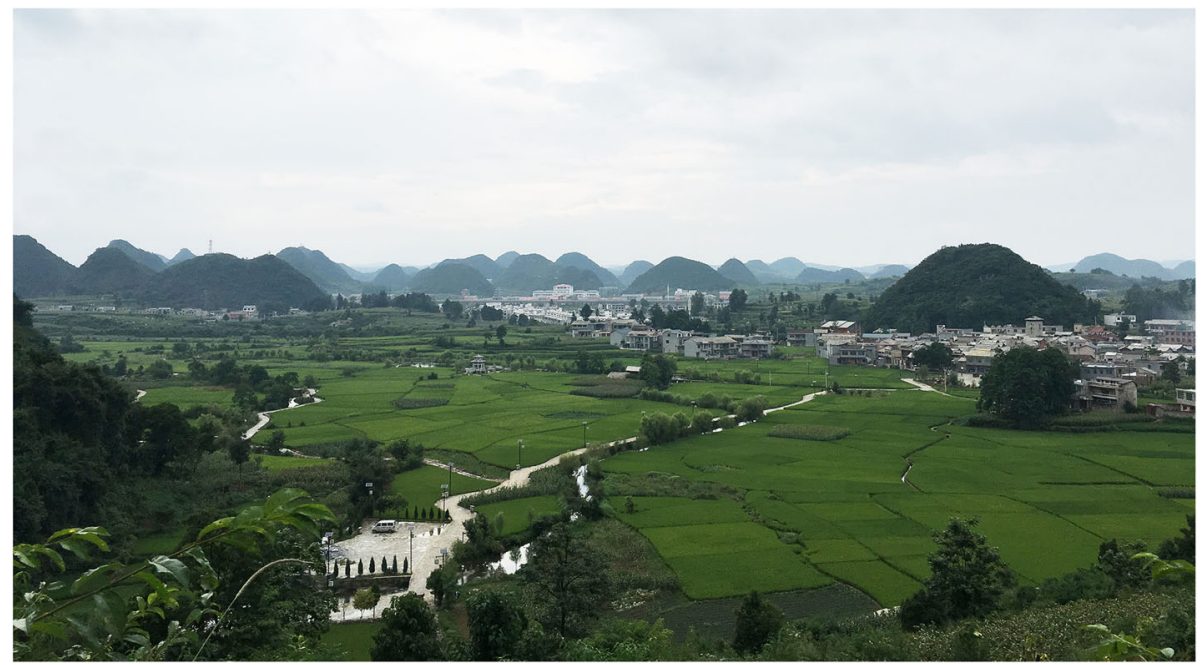

Fig. 2 Baojiatun Village on depressions surrounded by karst peaks (Source: the authors) 


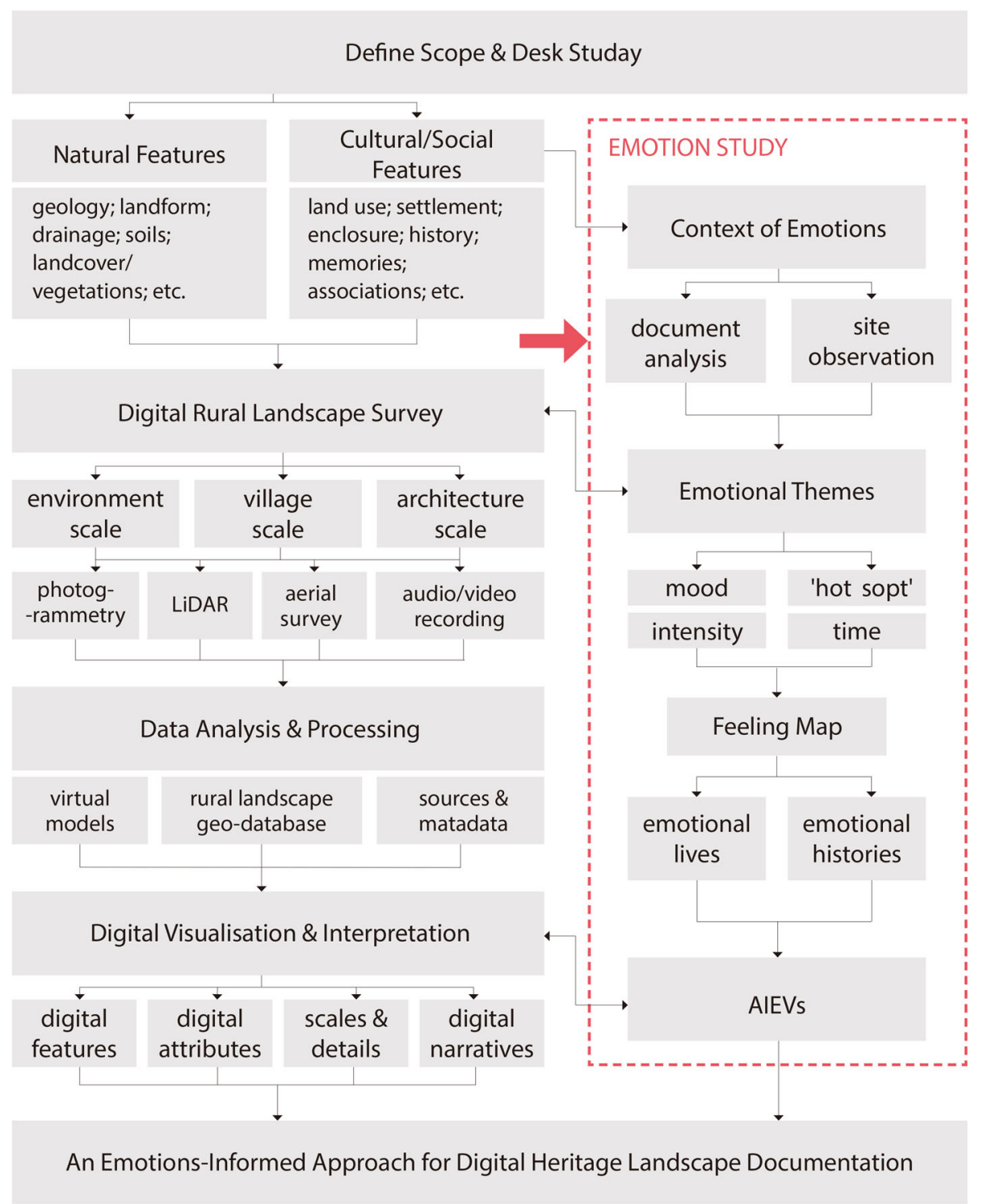

Fig. 3 A heritage documentation process with an emotion study before digital survey (Source: the authors)

opera performance, traditional folk craft and farming practices, and martial arts which occurred in specific sites within Baojiatun. The project team also recorded detailed interpretation provided by two local guides who, as part of contemporary heritage efforts, are routinely appointed by collective consensus among the local community to deliver narrated tours for visitors. The research team observed the sites at which these guides lingered during their tours of the village and the narratives and origin stories they developed in and for these locations and objects. In addition, informal interactions with local community (including two village committee members, three local amateur historians, two local guides and six other inhabitants), and observations of their behaviour and discussion at different sites, were used to supplement this analysis. The project team used open-ended questions during these conversations, including queries such as: Can you tell us about the history of your village? What are the important landscapes in your village? Which landscapes should be protected and interpreted? Unlike recordings of guided tours and interpretations, these conversations were not formalised as recorded interviews in light of perceived local sensitivities, but are included as a viable research methodology within this specific political and cultural context.

The project team then undertook an ethnographic content analysis to identify particular feelings and AIEVs of the local community of Baojiatun. The focus of this analysis was to identify specific landscape features, their associated meaning and value, and the emotions 
conveyed during the interviewee's interpretations of their village and culture. From the video recordings of the two local guides' oral interpretation of the village, 21 video clips were collected with a total length of $63 \mathrm{~min}$ and $15 \mathrm{~s}$. During the interview with the other six inhabitants, the project team recorded key information through written notes. Several important emotional assets were identified from the qualitative and descriptive content of the documentary evidence and data from community engagement. Based on analysis and open coding of video content and notes, the project team identified certain natural and cultural landscape features which had corresponding interpretation themes and feelings. The project team also documented collective emotional responses and shared interpretations of heritage features among different interviewees; then categorised and visualised these on a 'feeling map'. The project team noted repeated reference to certain assets, at varied scales, identified by local people as having and creating emotional meanings from them, or as having perceived historical emotional values. This map therefore identified landscape features which receive concentrated attention from the villagers, and the emotional themes expressed when describing these places and features. The feeling map and the related interpretations were then used as evidence for identifying AIEVs for this project, which informed the subsequent digital survey process and visualisation of virtual assets.

\section{Digital documentation of the AlEVs of Baojiatun}

\subsection{A feeling map and the AIEVs of Baojiatun}

As described above, the application of an emotionsbased approach informed the development of a 'feeling map' of Baojiatun Village, containing 29 landscape features or sites and 13 interpretation themes (Fig. 4). These landscape features and themes were grouped according to six overlapping emotional characteristics: (1) feelings of cultural pride (military culture/ family history/ family culture); (2) hope for environmental resilience; (3) sense of security; (4) the pursuit of ecological harmony; (5) thanksgiving to ancestors; and (6) pride in local material innovations (irrigation system/defensive system) (Fig. 4). These feelings comprise distinct assets with intense emotional values (perceived historic and living) within the local heritage landscape. The feeling map demonstrates that emotional resonance is attached to both natural and cultural landscape features, where the rivers and the irrigation canals are the strongest emotional landscape features in the village. Furthermore, emotional characteristics are often complex, dynamic, and interlinked. When talking about the irrigation systems, local communities expressed their pride in the village and gratitude to their ancestors, while simultaneously expressing their pursuit of environmental resilience and longing for ecological harmony.

Based on the feeling map, it was found that the landscape features to which feelings are attached can be layered into three groups of AIEVs. The following AIEVs are sites and features of significant cultural and emotional imagination, conveying emotional values that are a combination of perceived historic and living experiences. The identification, recording and representation of AIEVs based on digital survey data and the local architecture, climate, ecology, and intangible cultural heritage has led to a holistic understanding of the heritage landscape and more robust heritage documentation.

\subsubsection{Natural environment: resilience and ecological harmony in the Guizhou landscape}

In addition to local buildings and the water conservancy system, the natural environment and landscape features around Baojiatun were also endowed with rich emotional significance by the local community. The set of hills including Dajing Hill, Lion Hill, Yakou Hill, Elephant Hill, and the Spiral Shell Hill, in the southern part of the village, as well as the low-lying hills behind the village, all generate important emotional resonances and constitute an important AIEV (Fig. 5). These include the pursuit of ecological harmony, pride in the village, and gratitude to ancestors. During interpretation by the local guides, fengshui was repeatedly mentioned, and the concept of fengshui also elicited affirmation, respect, and pride during interviews with other inhabitants. Fengshui, literally translated as wind/water, is the Chinese philosophy underpinned by Taoist ideals of balance within interrelated environments. The observance and adherence of traditional Chinese practices of fengshui provide additional evidence for the existence of an emotional regime of ecological harmony. As a popular pre-modern concept, principles of fengshui permeated Chinese societies throughout history, shaping social relationships, emotional regulation, and the use of physical space and landscapes. In the case of Baojiatun, the integration of fengshui principles with the design of the village is a long and carefully-planned cultural geography, emphasising the importance of fengshui as a materialist approach for heritage which governs social ordering, emotional responses and management of human activity with traditional landscapes.

Principles of resilience and ecological balance are reflected and perpetuated by wider cultural ideas around subsistence within the unforgiving, impenetrable, and isolated geography of Guizhou, leading to an expressed desire for harmony within the landscape by local people. The ecological conditions of Guizhou, its climate and terrain, have long been considered by locals as part of the native tunpu 'cultural mood', and many of the tunpu 


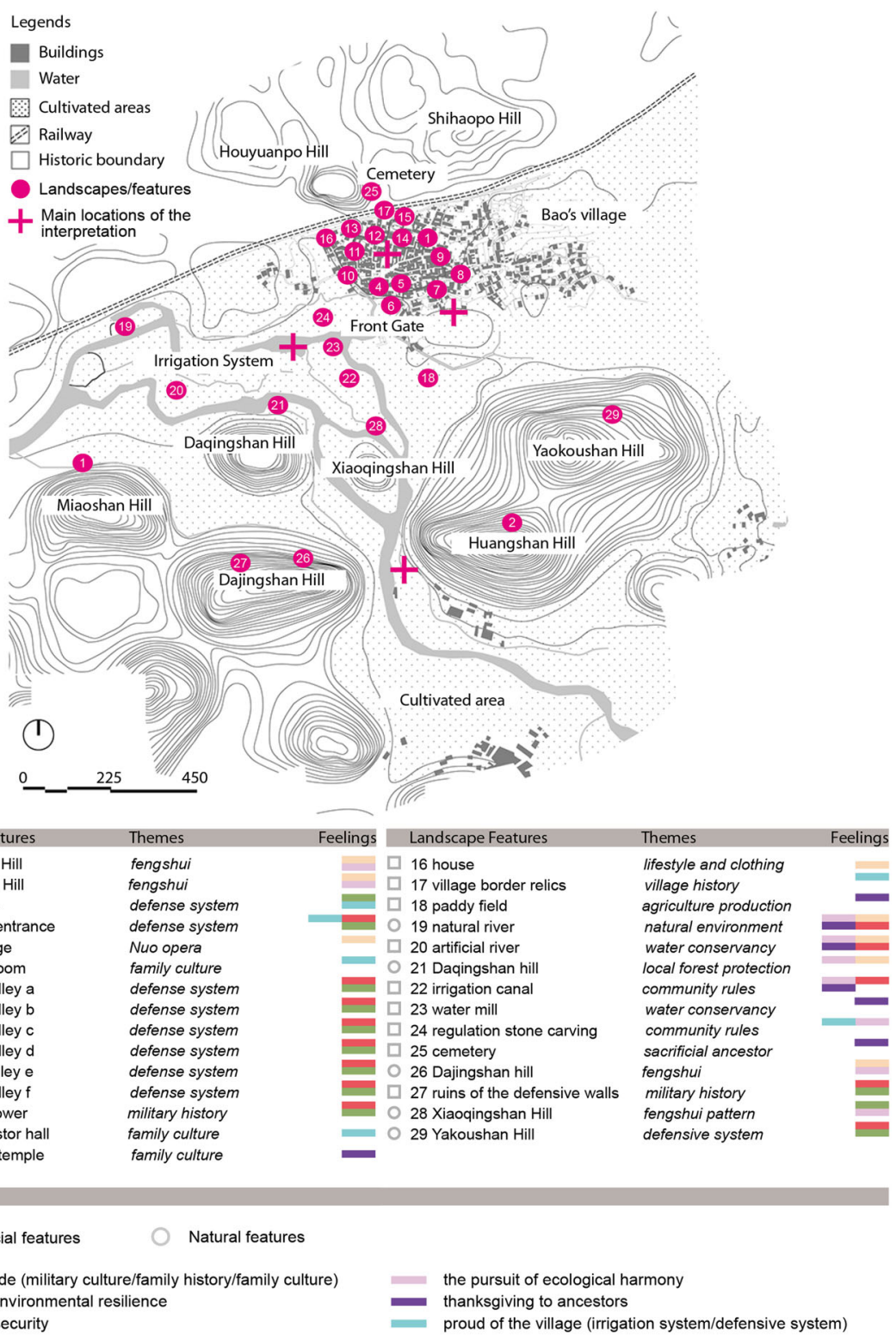

Fig. 4 A feeling map of Baojiatun Village (Source: the authors)

cultural narratives of liminality, insularity and survival are propagated by the inhabitants of traditional tunpu villages themselves. The natural landscape of Guizhou is described as a 'crumpled maze of mountains canyons and caves that inhibit internal integration', where hilly karst limestone formations make up over nicely percent of the province's land-mass (Oakes 2000, 685). The adverse farming conditions and wet weather of Guizhou are influencing the psyche and behaviour of its inhabitants and resulting in the cynically humorous local proverb 'No three days are clear, not three feet of land are level, and no one has three ounces of silver' as noted by Weinstein $(2014,11)$.
The natural environment, and the ideas about nature, have both historically and today, acted as significant components in the cultural practices of identity formation and embodied memorialisation (Johnson 2015). The unforgiving natural landscape of Guizhou as a materially-expressed 'emotional geography' extends a culture of insularity and provides the backdrop for the 'retention of group history and ideals' competing in this space over time (Lucas 2012). Social interactions and the realities of everyday life ground tunpu feelings and emotions in sensorial and embodied experience, resulting in a local identity governed by economic subsistence and a material regime of hardship tempered by emotional 


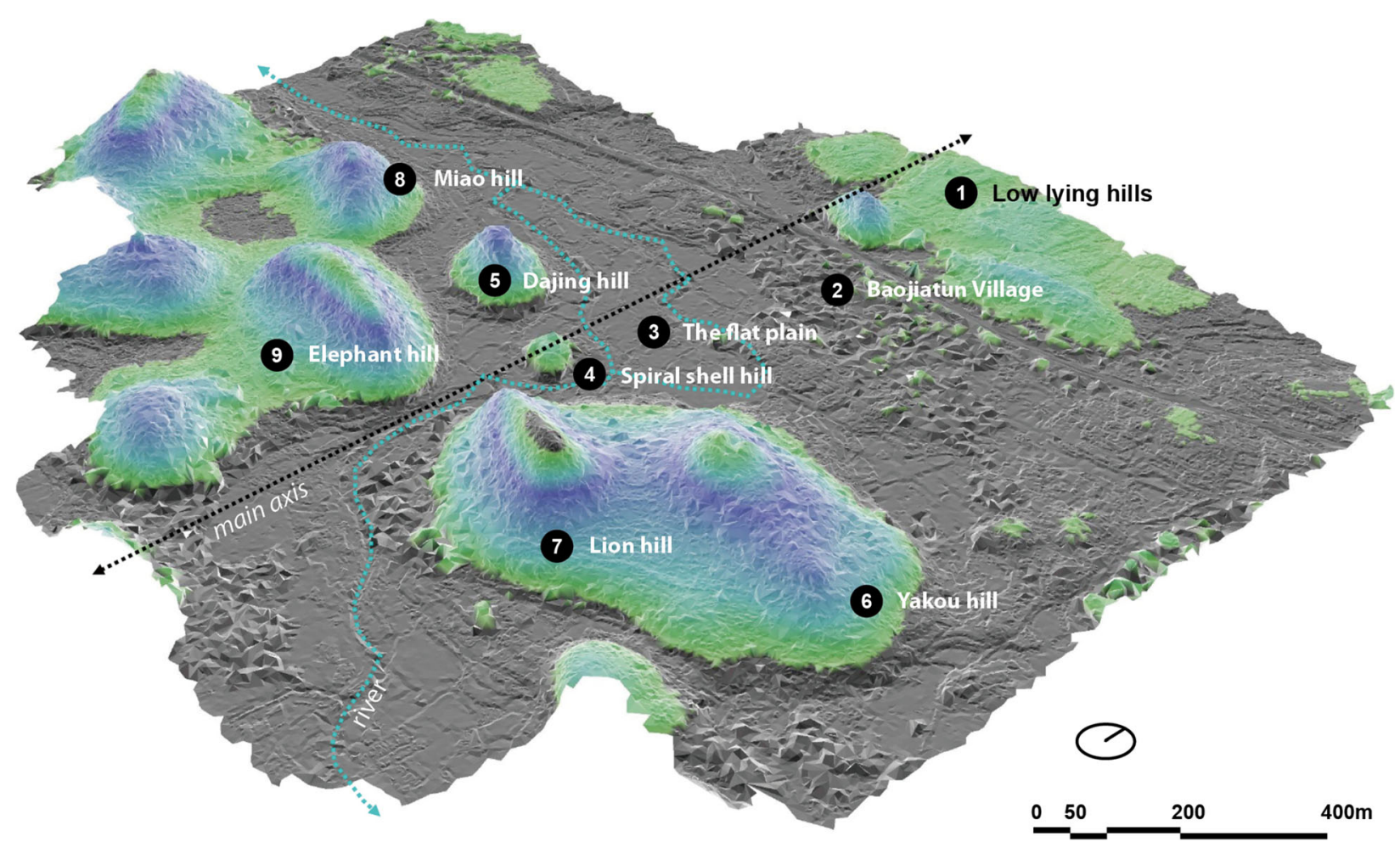

Fig. 5 Digital terrain model showing the geographical features of Baojiatun (Source: the authors)

resilience. The natural environment and features of Baojiatun therefore necessarily became a focus of digital documentation when the research team refined their understanding of the intense emotional relationships between tunpu inhabitants and their local surroundings.

\subsubsection{The irrigation and flood control system: community and environmental cohesion}

In contrast to the perceived combative aspects of material and intangible culture at Baojiatun and the challenges of subsistence and survival within the wider landscape, other local assets appear broadly to express more benign emotional registers of collective mindedness, communal behaviour, and environmental cohesion. On the feeling map, the local irrigation and flood control system, including the dams, the water mill, and the watercourses, were all interpreted by the local tour guides as iconic features of the village (Fig. 6). Local folklore posits that the system was first constructed using knowledge of water management and irrigation techniques brought by General Bao during the Ming Dynasty. A story circulated by the current inhabitants and passed down for generation explains that the different local tribes were united by Bao's work on the dam (Wu 2011). Of utmost importance has been the role of water system in 'lifestyle and being part of nature', and 'social cohesion' (Wu 2010, 81). Origin stories related to the founding of the village and construction of the dams by General Bao often feature in these 'emotionscapes', reinforcing a narrative overview of the village's history where association with the earliest Ming settlers in the area defines the village's sense of identity.

For centuries, the water management system has not only guaranteed safety and irrigation for the village, it also provided an important emotional and cultural bond for the local community. Irrigation and water management has been maintained by the occupants of Baojiatun throughout the centuries, with a strict prescribed social order that dictated responsibility for the maintenance and upkeep of particular parts of the system by particular familial lineages. Cooperative endeavour, where personal behaviour or conduct affects the local ecology, becomes highly apparent within the cultural context surrounding the system (Kau 1992). Prescribed responsibilities around the system demonstrate that the repair and maintenance of the system was considered to be a communal practice, carefully regulated by local conventions and interpersonal dependence (Wu 2011). These social practices reveal intimate emotional information about behaviours of collectivism within the tunpu cultural context, both in the past, and today, nuancing the concept of harmony as part of a culturally-exclusive emotion canon. The water management system incorporates an emotional heritage that not only reflects local knowledge, material craftsmanship and intangible cultural performance, but also ideas about sustainable communal living and ecological harmony. 

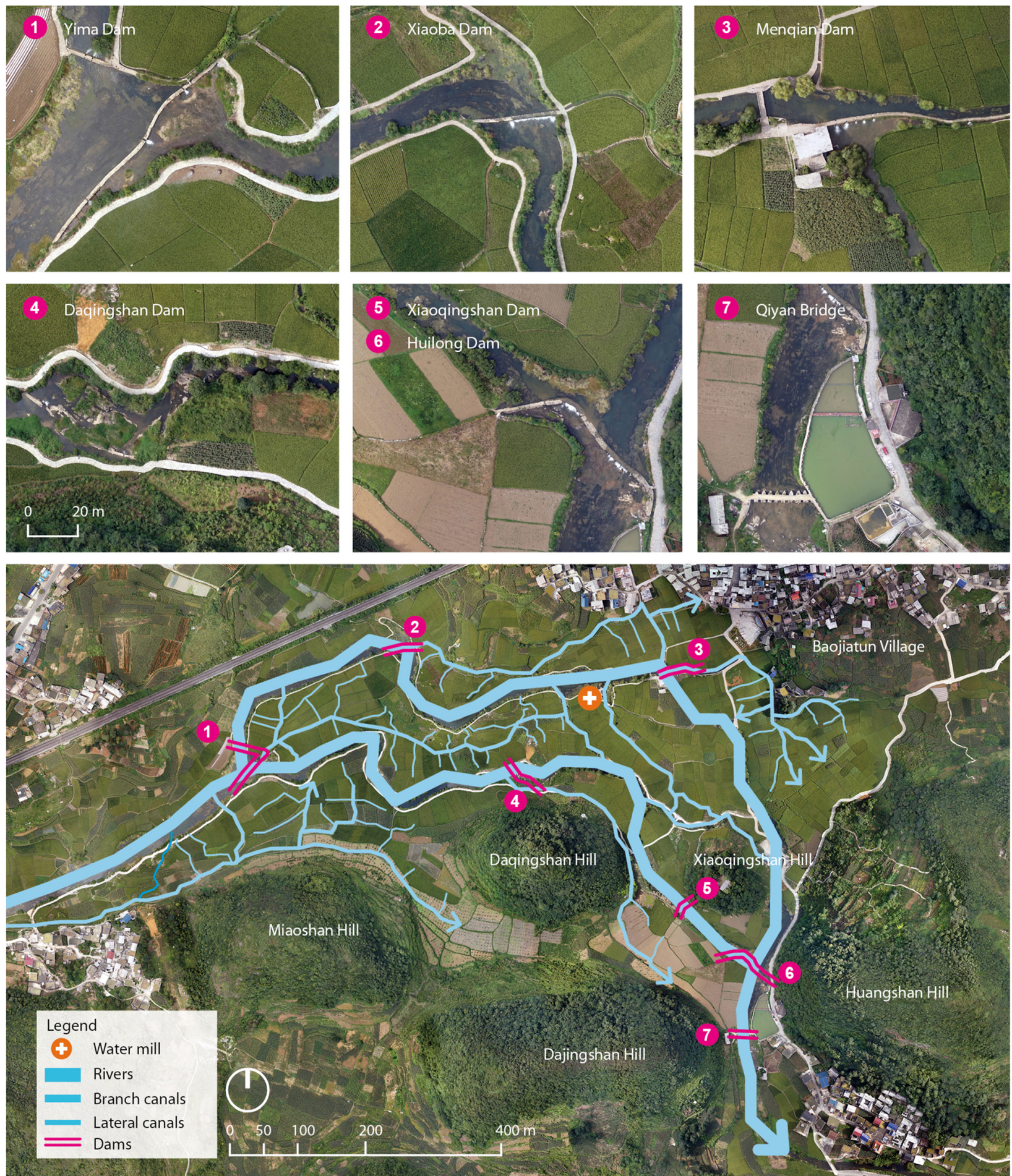

Fig. 6 Current condition of water management system and facilities recognised using digital high-precision orthophotos (Source: the authors)

The adoption of an emotions-based approach led us not only to pay attention to and record the technical value of the water management system, but also to pay attention to the intangible factors behind it-rural regulations and folk conventions, group responsibility, and the mechanism to form and sustain the landscape. The irrigation system, as a heritage feature, signifies and carries important cultural information and emotional connections between people and landscape in Baojiatun. It is therefore necessary to record these emotional 
connections and the local knowledge behind this interpretation of the landscape. The emotions-based documentation process inherently draws attention to the human factors of heritage, which play an important part in the formation and identification of local cultural identity. The challenge for heritage documentation is therefore not only the technical survey of the watercourses and dams, but the recording of its communal management and operation and the emotional ties which underpin these.

\subsubsection{Tunpu buildings: defensive preparedness and military pride with Baojiatun's built environment}

Military features and material evidence of defensive preparedness dominate the physical design of stone tunpu villages and buildings, articulating an emotional heritage overshadowed by conflict and external wariness of external communities. Through analysis of the feeling map, the project team identified that local residential structures of Baojiatun, consisting of easily defensible courtyard houses overlooking alleys within the village itself, were important landscape features with rich associated emotional meanings. In the early years of tunpu settlement, while most of these villages adopted farming and integrated with local indigenous populations of Guizhou, these colonies often came into conflict with other non-Han ethnic groups (Weinstein 2014). The main street of Baojiatun today, with its branching side lanes and defensive enclosure, demonstrate this emotional character of the village particularly well (Fig. 7). Housing styles and domestic architectural features are understood by locals to represent the martial character of tunpu society today where defensive architecture specifically designed to deter and repel invaders was popularised as a local built form throughout the town's history.

Типри people considered, and consider themselves, as both 'insiders' and 'outsiders' within the local region, with their claims to ancient Han heritage drawing upon

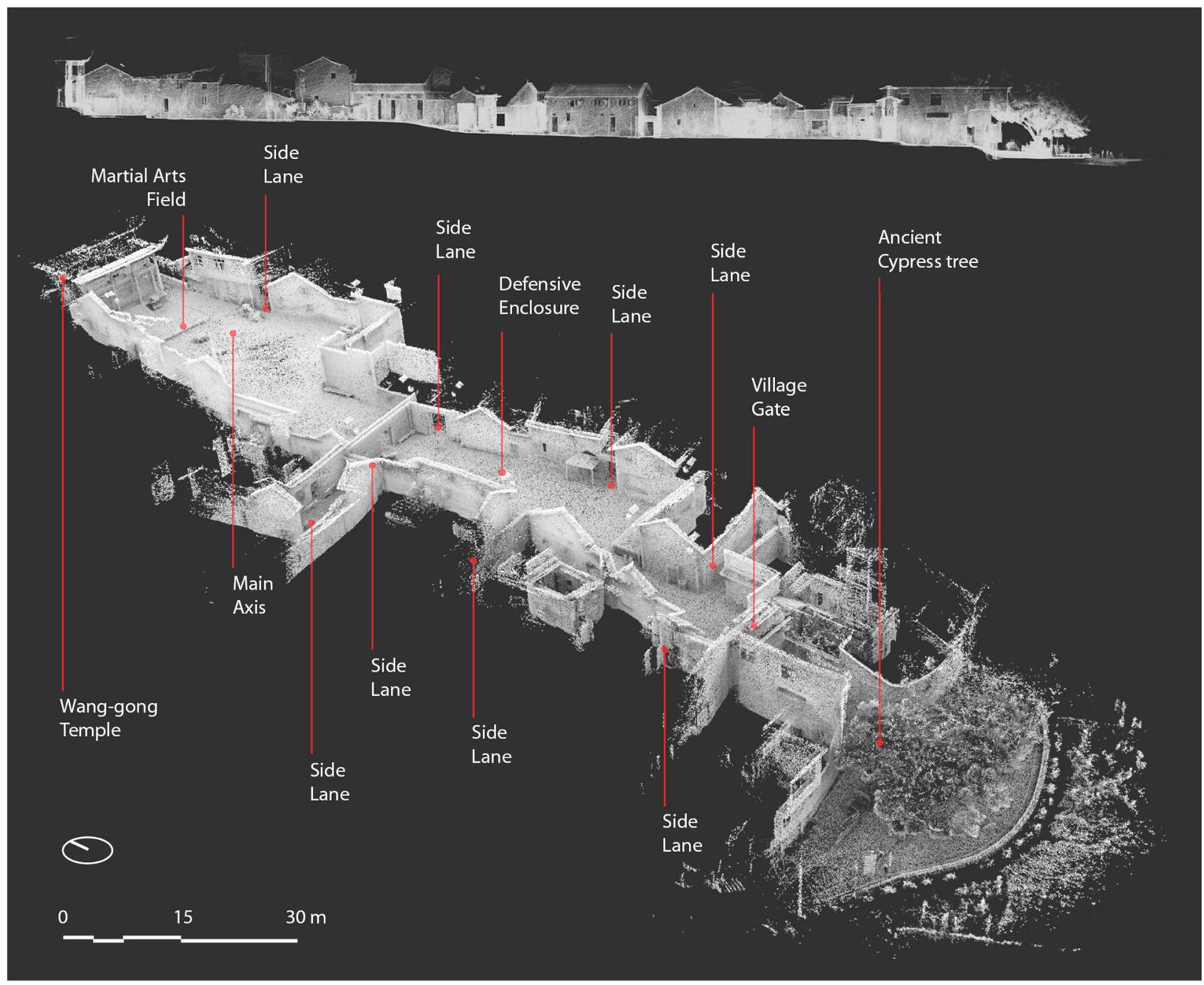

Fig. 7 A digital model of the main street of Baojiatun (Source: the authors) 
an ancient, established ancient Ming 'Chineseness' which set them apart from the region's other inhabitants. Preparedness and military pride are also reflected by the intangible heritage practices at Baojiatun today. Local martial arts and folk opera forms characterise affective experiences and memory of warfare and defence related to the physical properties of tunрu architectural style and landscape pattern. From the perspective of emotional heritage, these intangible heritage practices are all important emotional transmitters; and the sites at which they occur and their accompanying material artefacts should be recognised as important objects of heritage landscape documentation.

\subsection{An emotions-informed digital documentation of Baojiatun Village}

The scope and sensitivity of digital heritage documentation of Baojiatun was significantly expanded through the application of an emotions-informed approach and the interpretation of AIEV. The methodology outlined here digitally recorded aspects of the landscape not 'conventionally' recognised as heritage features but nonetheless featuring rich emotional resonances. In Baojiatun's past heritage registration documentation, only the water conservancy facilities and the surviving water mill were listed as objects of protection, and the surrounding natural environment was not included in the scope of cultural heritage conservation. However, this investigation has demonstrated that these landscape features have rich local values and historical connotations; and with the support of digital tools, can be accurately and completely recorded and represented using aerial drone survey data. The use and occupation of the landscape according to fengshui principles can also be directly visualised from the 3D model (Fig. 5), and stone buildings inside the village not previously afforded heritage status or documentation are now understood as sites with rich emotional meanings and can be documented using terrestrial laser survey and photogrammetry for particular decorative features.

This case study also demonstrates that the physical landscape environment and features are not the only objects for digital documentation, and their associated intangible cultural heritage components also need to be recorded. Digital mapping may be just one of the approaches to record the spatial features of heritage landscapes in the future. Other digital approaches may be designed and applied to record and interpret the activities, rules, and customs, and integrate emotional components into digital inventories. At the same time, dynamic landscape features in Baojiatun mean that the emotions and associated AIEVs are constantly changing. Digital documentation offers applications beyond a static 'record' as a dynamic and iterative platform and process.
Digital technologies can quickly, completely, and accurately measure and record landscapes, both in their tangible and intangible dimensions; and the application of an emotions-based approach extends existing opportunities to record heritage landscapes.

\section{Discussion and conclusion}

As a socially focused methodology, the emotionsinformed approach outlined here promotes the idea of heritage landscapes as living objects, and adds a necessary human-centred perspective to the accelerating technological process of digital surveying and mapping. As we have shown, an emotions-informed approach helps to identify the rich multi-level values of heritage landscapes, especially in their intangible cultural and social aspects. Compared with existing conservation programs and recording workflows for heritage landscapes, the approach outlined here has expanded the scope and recognition of rural building complexes to include the natural surrounding environment of the village. This has allowed us to examine heritage landscapes and the people and cultures within them more comprehensively and enables more responsible heritage conservation practice.

The sample AIEVs outlined above demonstrate that heritage sites, objects, rituals, and practices can elicit multiple and complex emotions of particular intensity. A focus on emotions thus has the capacity to reveal a cultural richness in relation to heritage and heritage landscapes that might otherwise go unacknowledged and undocumented. Based on the HLC method, this heritage emotions research further establishes a methodology which allows for a better-informed understanding of the heritage of both tunpu culture and Baojiatun Village during the production of digital survey data. Including emotions and identification of assets with intense emotional value in both heritage analysis frameworks and digitisation processes offers an interpretation of the past where senses and feelings are considered an inherent and fundamentally important part of heritage. The identification and interpretation of the AIEVs enables us to identify the key information from the huge data set of digital survey and to improve the digital documentation approach.

This new emotions-based approach also connects disparate aspects of heritage landscapes such as the water management system, architectural heritage, and the natural environment, leading to a holistic understanding of this heritage landscape. These heritage components were protected separately within the existing conservation program, which had previously lacked a fullyincorporated understanding of the whole landscape. People's emotions, as a strong link between these heritage features, can provide deeper understanding of the social- 
cultural context which can integrate different types of heritage; and the process of digital documentation allows for different aspects of heritage scope and scale to encompass these differing emotional perspectives. With the support of this new methodology, heritage documentation practices are no longer limited to rigid professional drawings, but storytelling using digital media to provide information support for the integrated conservation of heritage landscapes.

Finally, this method incorporates community participation in the process of digital survey and mapping so that heritage professionals can connect and engage with the local community to develop a better understanding of local cultural knowledge and values. Methods based on emotions research have bridged the gap between technical professionals and local communities, helping to accurately process and analyse data and develop more culturally appropriate heritage records and representations. Within many traditional villages, processes of modernisation may significantly alter or detract from perceived historic or cultural value of heritage features over time. However, this research has shown that all heritage features are part of the wider digitally-recorded emotional landscape, which can build a case for comprehensive heritage protection in the future. On this basis, one of the goals of this project is to enable surveying and mapping professionals to establish greater understanding and emotional connection to all aspects of heritage and culture. The process of community participation in understanding emotional engagement with heritage therefore promotes understanding of the value of the heritage environment and strengthens local cultural heritage practices.

\section{Abbreviations}

UNESCO: United Nations Educational, Scientific and Cultural Organisation; AIEV: Assets with Intense Emotional Value; HLC: Historic Landscape Characterisation

\section{Acknowledgements \\ The authors thank Professor Susan Broomhall for her important contributions to this paper. The case study was assisted by the Tourism Bureau of Anshun City and the Committee of Baojiatun Village. Special thanks to Rao Maozhong, Bao Zhongquan and Lu Yanping for their support for the on-site investigation. We are grateful to Shanghai Tongfan Surveying Engineering Technology Co., Ltd. and Shanghai Fengyu Culture Communication Co., Ltd. for their support in data collection and processing.}

\section{Authors' contributions}

All authors read and approved the final manuscript.

\section{Funding}

This work was supported by funding from the Australian Research Council Centre of Excellence for the History of Emotions (CE1101011); and the Institute for Advanced Studies, The University of Western Australia. It was also supported by the 111 Project (project number: B16035); and Research Project of the Built Environment Technology Centre, College of Architecture and Urban Planning, Tongji University (No. 2020100302).

Availability of data and materials Not applicable.

\section{Declaration}

\section{Competing interests}

The authors declare that they have no competing interests.

\section{Author details}

${ }^{1}$ Faculty of Arts, Business, Law and Education, The University of Western Australia, 35 Stirling Highway (M208), Crawley, WA 6009, Australia.

${ }^{2}$ Department of Landscape Architecture, College of Architecture and Urban Planning, Tongji University, 1239 Siping Road, Shanghai 200092, People's Republic of China. ${ }^{3}$ Key Laboratory of Ecology and Energy-saving Study of Dense Habitat, Ministry of Education, Shanghai, People's Republic of China. ${ }^{4}$ Department of Landscape Architecture, School of Architecture, Southeast University, Nanjing 211189, People's Republic of China.

Received: 16 August 2020 Accepted: 16 June 2021

Published online: 05 July 2021

\section{References}

Ahmed, Sara. 2004. The cultural politics of emotion. Abingdon: Routledge.

American Psychological Association. 2021. "American Psychological Association." Accessed 25 Mar 2021. https://apa.org.

Baptista, Maria Lucia Vianna. 2013. Documenting a complex modern heritage building using multi image close range photogrammetry and 3D laser scanned point clouds. In Paper presented at The International Archives of the Photogrammetry, Remote Sensing and Spatial Information Sciences, Strasbourg, France.

Broomhall, Susan, and Gina Pickering, eds. 2012. Rivers of emotion: An emotional history of Derbarl Yerrigan and Djarlgarro Beeliar / the Swan and Canning Rivers. Perth: Uniprint.

Cormier, Brendan. 2017. Copy culture: Sharing in the age of digital reproduction. Accessed 03 Jan 2021. https://vanda-production-assets.s3.amazonaws.com/2 018/06/15/11/42/57/e8582248-8878-486e-8a28-ebb8bf74ace8/Copy\%2 oculture.pdf.

Domínguez-Quintero, Ana, M. González-Rodríguez, and José Luis Roldán. 2019. The role of authenticity, experience quality, emotions, and satisfaction in a cultural heritage destination. Journal of Heritage Tourism 14 (5-6): 491-505. https://doi.org/10.1080/1743873X.2018.1554666.

Fairclough, Graham, and Pete Herring. 2016. Lens, mirror, window: Interactions between historic landscape characterisation and landscape character assessment. Landscape Research 41 (2): 186-198. https://doi.org/10.1080/0142 6397.2015.1135318

Flynn, Bernadette. 2007. The morphology of space in virtual heritage. In Theorising digital cultural heritage: A critical discourse, ed. Fona Cameron and Sarah Kenderdne. Cambridge: The MIT Press. https://doi.org/10.7551/ mitpress/9780262033534.003.0018.

Johnson, Nuala C. 2015. Heritage and geography. In The Palgrave handbook of contemporary heritage research, ed. E. Waterton and S. Watson, 159-173. Basingstoke: Palgrave McMillan. https://doi.org/10.1057/9781137293565_10.

Kau, Y.L. 1992. The Chinese Feng Shui. Beijing: China Fua Chiao.

Keightley, Emily, and Michael Pickering. 2012. The mnemonic imagination: Remembrance, remembering as creative practice. Basingstoke: Macmillan. https://doi.org/10.1057/9781137271549.

Kivilcim, C.O., and Z. Duran. 2016. A semi-automated point cloud processing methodology for 3D cultural heritage documentation. In XXIII ISPRS congress, commission V (Vol.41), ed. L. Halounova, V. Safar, F. Remondino, J. Hodac, K. Pavelka, M. Shortis, F. Rinaudo, M. Scaioni, J. Boehm, and D. RiekeZapp, 293296. Gottingen: Copernicus Gesellschaft Mbh.

Lennon, Jane. 2012. Cultural landscape management: International influences. In Managing cultural landscapes, ed. Ken Taylor and Jane Lennon, 45-69. Abingdon: Routledge.

Liebelt, Belinda. 2019. Touching grindstones in archaeological and cultural heritage practice: Materiality, affect and emotion in settler-colonial Australia. Australia Archaeology 85 (3): 267-278. https://doi.org/10.1080/03122417.201 9.1751982.

Lucas, Patrick. 2012. Local narrative and outsider imagination in a Chinese landscape: Materiality, sense and agenda. Focaal: Journal of Global and Historical Anthropology 64: 69-83.

Luo, Jianping. 2014. Anshun tunpu de fangyuxing yu diquxing [Defensiveness and Regionality of Anshun Tunpu]. Beijing: Tsinghua University Press. 
Marchant, Alicia. 2019. Mapping an archive of emotions: Place, memory and the affective histories of Perth's Riverscape. In Routledge handbook of new digital practices in galleries, libraries, archives, museums and heritage sites, ed. Hannah Lewi, Wally Smith, Dirk vom Lehn, and Stephen Cooke. Abingdon: Routledge.

Oakes, Tim. 2000. China's provincial identities: Reviving regionalism and reinventing 'Chineseness'. The Journal of Asian Studies 59 (3): 667-692. https://doi.org/10.2307/2658947.

Quintero, Santana, Mario Reem Awad, and Luigi Barazzetti. 2020. Harnessing digital workflows for the understanding, promotion and participation in the conservation of heritage sites by meeting both ethical and technical challenges. Built Heritage 4 (1): 7-24. https://doi.org/10.1186/s43238-02000005-7.

Reckwitz, Andreas. 2012. Affective spaces: A Praxeological outlook. Rethinking History 16 (2): 241-258. https://doi.org/10.1080/13642529.2012.681193.

Sather-Wagstaff, Joy. 2016. Making Polysense of the world: Affect, memory, heritage. In Heritage, affect and emotion: Politics, practices and infrastructures, ed. Divya P. Tolia-Kelly, Emma Waterton, and Steve Watson, 12-30. New York: Routledge.

Smith, Laurajane, Margaret Wetherell, and Gary Campbell. 2018. Emotion, affective practices, and the past in the present. Oxon and New York: Routledge. https:// doi.org/10.4324/9781351250962.

Turk, Catherine Schroeder. 2019. Placemarks on watermarks mapping, sensing and sampling the 'Rivers of Emotion'. Cartographic Perspectives 91: 96-113.

Turner, Sam. 2006. Historic landscape characterisation: A landscape archaeology for research, management and planning. Landscape Research 31 (4): 385-398. https://doi.org/10.1080/01426390601004376.

UNESCO. 2003. Charter on the Preservation of Digital Heritage. The Records of the 32nd Session of the General Conference, volume 1 resolutions. Paris: UNESCO.

UNESCO. 2009. World heritage cultural landscapes: A handbook for conservation and management. Paris: World Heritage Centre, United Nations Educational, Scientific and Cultural Organisation.

UNESCO. 2012. UNESCO/UBC Vancouver Declaration. The Memory of the World in the Digital Age: Digitization and Preservation. Paris: UNESCO. http://www. unesco.org/new/fileadmin/MULTIMEDIA/HQ/CI/Cl/pdf/mow/unesco_ubc_va ncouver_declaration_en.pdf. Accessed 10 May 2021.

Weinreb, Amelia Rosenberg, and Yodan Rofè. 2013. Mapping feeling: an approach to the study of emotional response to built environment and landscape. Journal of Architectural and Planning Research 30 (2): 127-145.

Weinstein, Jodi L. 2014. Empire and identity in Guizhou: Local resistance to Qing expansion. Seattle: University of Washington Press.

Williamson, Tom. 2007. Historic landscape characterisation: Some queries. Landscapes 8 (2): 64-71. https://doi.org/10.1179/lan.2007.8.2.64.

Wu, Qingzhou. 2010. "Guizhou xiao Dujiangyan-Anshun Baotun shuili." [The Small Dujiang Weir, Baotun Water Conservancy Project in Anshun, Guizhou.]. South Architectural 4: 78-82.

Wu, Qingzhou. 2011. The heritage conservation practical case: Baojiatun watermill. In The best in heritage: Projects of influence. European Heritage Association Accessed 12 Nov 2017. http://presentations.thebestinheritage. com/2012/Baojiatun\%20Watermill\%20in\%20Guizhou\%20Province.

Wu, Yu, and Wenjing Gong. 2009. "Tunpu wenhua yanjiu shuping." [A Research Review of the Studies on Tunpu Culture]. Guizhou Ethnic Studies 29(2):96-97.

Yang, Chen. 2015. Using an 'interpretative model' for contextual design of heritage landscape databases: The case of St Helena Island National Park in Queensland, Australia. Geographical Research 53 (3): 321-335. https://doi. org/10.1111/1745-5871.12117.

\section{Publisher's Note}

Springer Nature remains neutral with regard to jurisdictional claims in published maps and institutional affiliations.

\section{Submit your manuscript to a SpringerOpen ${ }^{\circ}$ journal and benefit from:}

- Convenient online submission

Rigorous peer review

- Open access: articles freely available online

- High visibility within the field

- Retaining the copyright to your article

Submit your next manuscript at $\boldsymbol{\nabla}$ springeropen.com 